\title{
A comparison of soil-water distribution under ridge and bed cultivated potatoes
}

\author{
David Robinson $^{1}$ \\ Institute of Hydrology, Wallingford, Oxfordshire OX10 8BB, UK
}

Accepted 28 January 1999

\begin{abstract}
Data is presented comparing infiltration of irrigation and rain water to potato crops planted in ridges and beds in East Anglia, UK. An automatic soil water station (ASWS) was used to monitor soil water content and potential in the two cultivation systems. The ASWS data indicated that most of the water bypassed the potatoes planted in ridges as irrigation water applied to the crop from a boom irrigator was shed off the ridges infiltrating in the furrows. This was due to the water repellent nature of the sandy soil and meant that the irrigation water bypassed the potatoes. A soil water deficit built up in the core of the ridge as the crop grew and was not replenished by irrigations. A second early potato crop planted in beds was more successful at capturing water as the flat bed increased water infiltration around the crop. This has major implications for cultivation practice, scab control and crop water management. Instruments measuring soil water potential, content, temperature and rainfall were connected to a data logger powered by a solar panel and proved a successful way of monitoring infiltration. Hourly data was collected so that a high temporal resolution data set could be constructed in order to increase conceptual understanding of hydrological processes at a scale appropriate to the crop. (C) 1999 Elsevier Science B.V. All rights reserved.
\end{abstract}

Keywords: Potatoes; Irrigation; Dielectric sensors; Ridge cultivation; Bed cultivation

\section{Introduction}

In the UK, potatoes are the most important of the irrigated crops in terms of area and volume of water applied. In 1990 potatoes covered 32\% of the area under irrigation and used $\sim 50 \%$ by volume of the applied irrigation water (Stansfield, 1996). During 1995 and

\footnotetext{
${ }^{1}$ Present address: The Institute of Soils, Water and Environmental Sciences, The Volcani Centre, Bet Dagan, Israel.

E-mail address: vwdrobin@agri.gov.il (D. Robinson)
} 
1996 the UK suffered two very dry years causing pressure on growers to improve water use efficiency. Efficient use of water can only be achieved by gaining a firm conceptual understanding of soil water movement and distribution under a crop at a scale relevant to the plant. This knowledge can then be used to determine the best way to apply water.

The potato market is highly competitive and in order to remain so, good water management is required to maintain crop quality, prevent diseases such as scab, while maintaining the efficient use of water. At present the Ministry of Agriculture in the UK recommends that a deficit of no greater than $15 \mathrm{~mm}$ is allowed to develop in the soil so that the surface of the potato is kept moist to prevent infection by scab. In terms of total water potential, it should go no lower than $-20 \mathrm{kPa}$ (Bailey, 1990). In order to monitor the soil moisture regime around the potato crop data is required which comes from close proximity to the crop at regular enough time intervals so that rapid infiltration events can be monitored. This paper presents data comparing infiltration into the soil under the more traditional ridge and furrow cultivation with bed cultivation.

Until recently instruments for soil moisture monitoring have required manual reading, e.g. the neutron probe for measuring soil water content and manometer tensiometers for measuring soil water potential. Advances in electronics and instrumentation have led to the development of new stand alone techniques. Utilisation of the dielectric properties of soils has led to a variety of techniques which measure soil relative permittivity, formally called dielectric constant (Topp et al., 1980; Dean, 1994; Gaskin and Miller, 1996); from which soil volumetric water content can be accurately estimated $( \pm 2 \%)$. Techniques such as time domain reflectometry (TDR) (Topp et al., 1980; Topp and Davies, 1985) and capacitance probes (Dean, 1994; Perdok et al., 1996) are safe, rapid, loggable and can be used to within a few centimetres of the soil surface depending on instrument configuration. Tensiometers linked to a pressure transducer can be attached to a logger for continuous monitoring in their working range $(0-80 \mathrm{kPa})$.

The TDR technique was used by Singh et al. (1993) to provide soil water content measurement for validation of an irrigation scheduling model for potatoes. Measurements were only taken weekly; the strengths of this instrumentation lie in its ability to measure hourly or at smaller time scales. The ASWS (automatic soil water station) provides measurement of soil water content, potential and soil temperature at a series of depths within the soil; a rain gauge provides data on water inputs. Measurements provide highresolution temporal data which is required to gain conceptual understanding of the soil hydrological processes around a crop. Similar instrumentation was used by Haria et al. (1994) to provide an understanding of sub-surface soil water processes.

\section{Materials and methods}

\subsection{Site and soil description}

The experimental fieldwork was carried out at Upton Suffolk Farms, Park Farm, Herringswell, Suffolk, UK. The soil was Red Lodge series within the Soil Survey of England and Wales classification (Avery, 1980). It is a sand and has an Ap horizon that is 
Table 1

Particle size and soil data from the field site at Park Farm

\begin{tabular}{lllllll}
\hline $\begin{array}{l}\text { Soil } \\
\text { horizon }\end{array}$ & $\begin{array}{l}\text { Sand } \\
\%\end{array}$ & $\begin{array}{l}\text { Silt } \\
\%\end{array}$ & $\begin{array}{l}\text { Clay } \\
\%\end{array}$ & $\begin{array}{l}\text { Total organic } \\
\text { carbon } \%\end{array}$ & pH & $\begin{array}{l}\text { EC 1:5 } \\
\text { extract S m }\end{array}$ \\
\hline Ap & 93.5 & 4.2 & 0.3 & 2.0 & 6.5 & 0.0295 \\
\hline
\end{tabular}

about $0.5 \mathrm{~m}$ in depth overlying a coarser sand. Both horizons contain flints and are de-stoned twice a year. Table 1 gives some of the soils properties.

\subsection{Water repellency}

The intensive cultivation and practice of reworking crop foliage back into the soil has led to the development of a soil that is water repellent, and particularly so when the surface has been allowed to dry. The water repellency of the soil was measured by the water drop penetration time test (WDPT) (Krammes and DeBano, 1965). A soil sample which was air dry was packed into a 1.51 cylinder, $0.1 \mathrm{~m}$ in diameter. Ten drops of water were applied, using a dropper, to the surface of the air dried soil sample. The times taken for the water droplets to penetrate into the soil were measured. This procedure was carried out with the soil packed to five bulk densities between 1.35 and $1.65 \mathrm{~g} \mathrm{~cm}^{-3}$; representative of the soil in the field. The WDPT test groups soils into five classes according to the time taken for water penetration. A soil is considered to be wettable if the penetration time is under $5 \mathrm{~s}$ and increasingly water repellent for times longer than this.

\subsection{Crop and cultivation information}

Two early potato crops were the focus of the study, the first grown in ridges and the second in beds. The first crop was the Maris Bard variety, planted on the 10th of March (Day of the year, DOY 69) and harvested in the final week of June 1997 (DOY 170). The potatoes were planted in ridges which were $0.20 \mathrm{~m}$ high (i.e., from the crest of the ridge to the base of the furrow) and the ridge top, centre spacing was $0.75 \mathrm{~m}$. The potatoes were planted at a depth of $0.14 \mathrm{~m}$ and a spacing of $0.15 \mathrm{~m}$ along each ridge. The canopy began to emerge around the 10th of April (DOY 100). The second early potato crop, which was the Carlingford variety, was planted on the 9th of July (DOY 190) and harvested in the final week of September 1997 (DOY 273). The potatoes were planted in beds $1.25 \mathrm{~m}$ in width, with a $0.6 \mathrm{~m}$ wide and $0.2 \mathrm{~m}$ deep furrow on either side. Three tubers were planted across the bed at a depth of $0.1 \mathrm{~m}$ and spacing of $0.15 \mathrm{~m}$ (the spacing along the bed was also $0.15 \mathrm{~m}$ ). Emergence was noted around the 25th of July (DOY 205).

\subsection{Irrigation}

Irrigation water was applied via a hosereel boom irrigator which applied water along a width of $72 \mathrm{~m}$ of soil. The irrigator took approximately one and a half minutes to apply $\sim 19 \mathrm{~mm}$ of water to a given point on the soil surface. A single drag of the 
boom irrigator covered a distance of $330 \mathrm{~m}$ and took approximately $8 \mathrm{~h}$. Irrigation began in April in order to wet the surface soil. From mid May it was applied on a 5-day rota where possible to prevent a deficit greater than $15 \mathrm{~mm}$ from building up and so act as a scab control.

\subsection{Automatic soil water station (ASWS)}

The ASWS comprised: a tipping bucket rain gauge, (calibrated to measure rainfall in $0.5 \mathrm{~mm}$ increments), three pressure transducer tensiometers to measure soil water potential, three capacitance probes to estimate water content and three thermistors to measure temperature. These were all connected to a Campbell CR 10 data logger which was set to record measurements hourly. The logger was powered by a $12 \mathrm{~V}$ battery, trickle charged from a solar panel which avoids cables being stretched across the field and interfering with agricultural practice. The soil sensors were installed at $0.15,0.25$ and $0.5 \mathrm{~m}$ depth below the top of the ridge/bed. The ASWS data was supported by manual field observations which were required to link above ground activities with below ground measurements. This included digging into the ridges at different times to observe the wetting patterns in the soil.

The capacitance probes at 0.15 and $0.25 \mathrm{~m}$ were installed by digging back the soil and inserting the electrodes horizontally into an undisturbed soil face between two sets of potato plants; the hole was then carefully back filled with soil. The probe installed at $0.5 \mathrm{~m}$ depth was inserted via a plastic access tube inserted into the ridge at $45^{\circ}$.

The pressure transducer tensiometers were manufactured at the Institute of Hydrology (Wallingford, Oxon, UK). The tensiometers were installed vertically about $0.5 \mathrm{~m}$ apart through access tubes, $50 \mathrm{~mm}$ in diameter. Each tensiometer was constructed with a high quality pressure transducer mounted $0.12 \mathrm{~m}$ above the middle of a $0.04 \mathrm{~m}$ long porous ceramic cup. Each could be filled with water and purged of air from the soil surface without the need to remove the instrument. Prior to installation the tensiometers were filled with de-aired water, then installed after wetting of the porous cup had been observed.

The thermistors were installed down an augured hole which was back filled. The thermistors were cylindrical, $80 \mathrm{~mm}$ in length and $5 \mathrm{~mm}$ in diameter and measured accurately to within $0.1^{\circ} \mathrm{C}$.

\subsection{Capacitance probe calibration}

The capacitance probes were calibrated to measure apparent relative permittivity according to the procedure presented in Robinson et al. (1998). Calibration between volumetric water content and apparent relative permittivity was conducted using repacked soil in the laboratory. Air dried soil was repacked into a plastic container $0.1 \mathrm{~m}$ in diameter and $0.15 \mathrm{~m}$ deep. A capacitance probe with $0.1 \mathrm{~m}$ electrodes was inserted into the soil and a measurement recorded. The soil was repacked to a different bulk density and a further measurement was taken. Measurements were taken at five bulk densities and then a sample of soil was removed for oven drying to determine the volumetric water content. The soil was then wetted with approximately $100 \mathrm{ml}$ of water and the procedure 
repeated. In all about 30 measurements were made at different bulk densities in order to achieve a comprehensive calibration curve.

\section{Results and discussion}

\subsection{Soil water repellency}

The water drop penetration times for the Red Lodge soil fell into, or close to, class 2 which is the slightly water repellent class (Fig. 1). The scatter in the data is likely to be a function of the scale at which the measurements were taken and spatial variability of the soil surface. The measured bulk density was an average of the 1.51 of soil used in this test but this may have varied locally at the surface of the cylinder due to packing. The overall consistency of the results, all falling in the same water repellency class, suggests the test is representative of the soil in general and that water repellency class does not alter greatly as a function of bulk density.

\subsection{Capacitance probe calibration}

The calibration based on the method of Gardner et al. (1998) is shown in Fig. 2. Linear regression was used to give a soil specific calibration (Eq. (1)) between water content and sqrt apparent permittivity $(K)$.

$$
\theta=\frac{\sqrt{K}-1.42}{12.34} \quad\left(R^{2}=0.995\right)
$$

ASWS results; first potato crop (ridge cultivation).

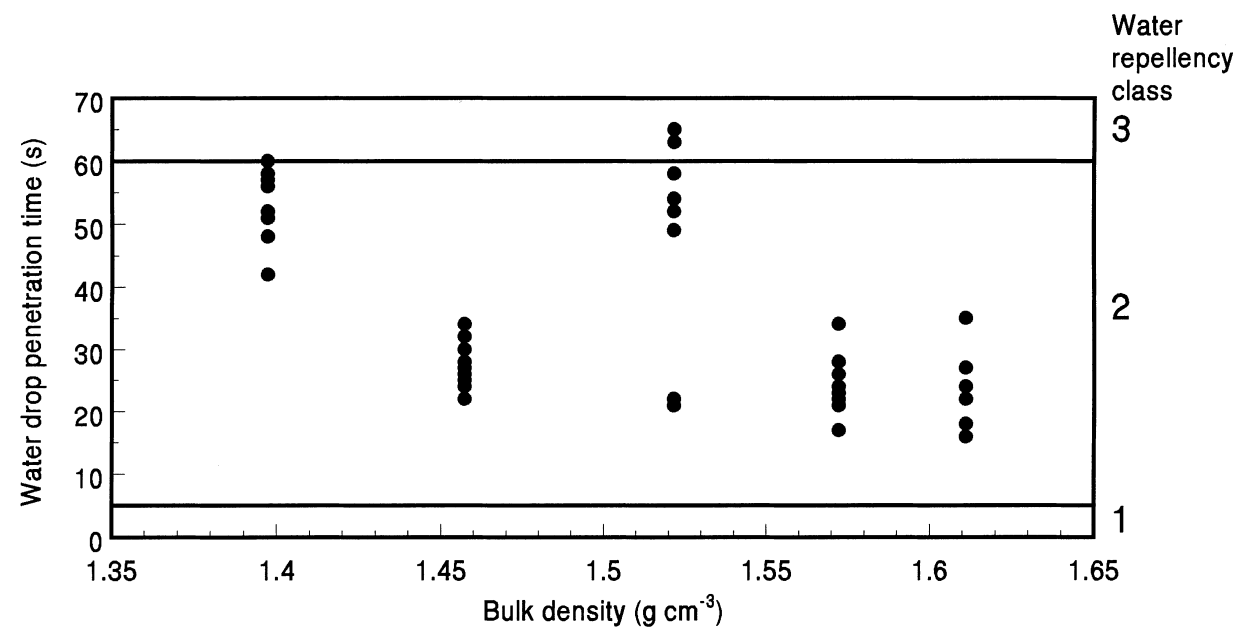

Fig. 1. The water drop penetration times for the Red Lodge soil at a range of bulk densities. 


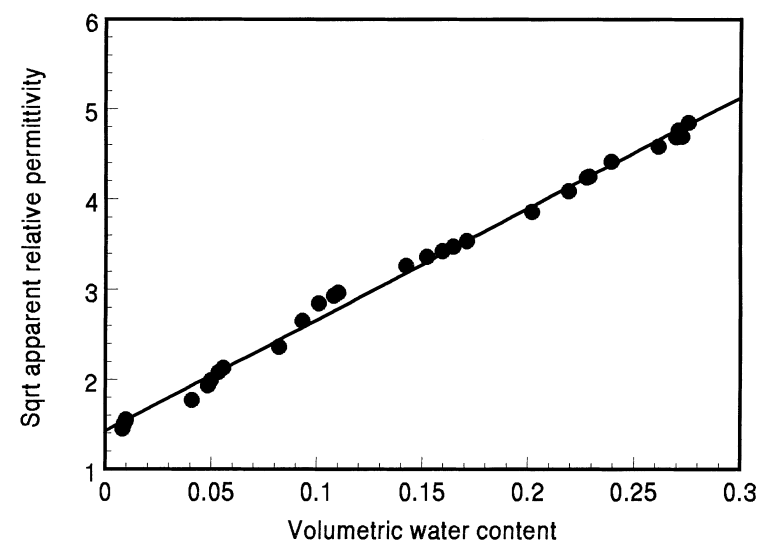

Fig. 2. Capacitance probe calibration $\sqrt{K}$ ( $K$ is apparent relative permittivity) in terms of volumetric water content.

\subsection{Rainfall and irrigation}

The ASWS was installed for 91 days during which $123 \mathrm{~mm}$ of rain fell on the field and $124.5 \mathrm{~mm}$ of irrigation was applied giving a total of $247.5 \mathrm{~mm}$ of water. The aim of each irrigation was to apply $19 \mathrm{~mm}$ of water; in practice irrigations averaged $20.8 \mathrm{~mm}$, with a standard deviation of $2.6 \mathrm{~mm}$. The distribution of the rainfall and irrigation inputs over time can be seen in Fig. 3(a).

\subsection{Soil water content, potential and temperature}

At the start of the season the soil was cultivated and ridged for the potatoes. The surface of the soil dried and acted as a mulch so that very little soil water was lost by evaporation from the bare soil surface. The data for the first crop obtained with all the sensors installed in the field are presented in Fig. 3. During the growth of the crop the soil volumetric water content remained between 0.15 and 0.05 . The soil water potential measured by the tensiometers followed the soil water content as one would expect. The potentials remained above $-80 \mathrm{kPa}$ until 2 weeks before the crop was harvested. The soil temperatures were observed to rise from about $10^{\circ} \mathrm{C}$ at the planting of the crop to about $16^{\circ} \mathrm{C}$ by the time the crop was harvested. Diurnal fluctuations in temperature were observed in both the soil water potential and the soil water content.

Fig. 3(b) shows the soil water contents measured by the sensors installed at depths of $0.15,0.25$ and $0.5 \mathrm{~m}$. During the first 10 days after the installation of the ASWS, soil water content changed negligibly. This soil water content of 0.11 in the ridge and 0.12 in the more compact, lower depths in the soil was considered to be field capacity. For this soil, field capacity at these water contents was supported by the soil matric potentials of $-10 \mathrm{kPa}$ measured by the tensiometers Fig. 3(c).

As the crop began to emerge (day 100) so the water content sensors at 0.15 and $0.25 \mathrm{~m}$ responded, showing drying. The first irrigation was applied on day 104 but the 0.15 and 


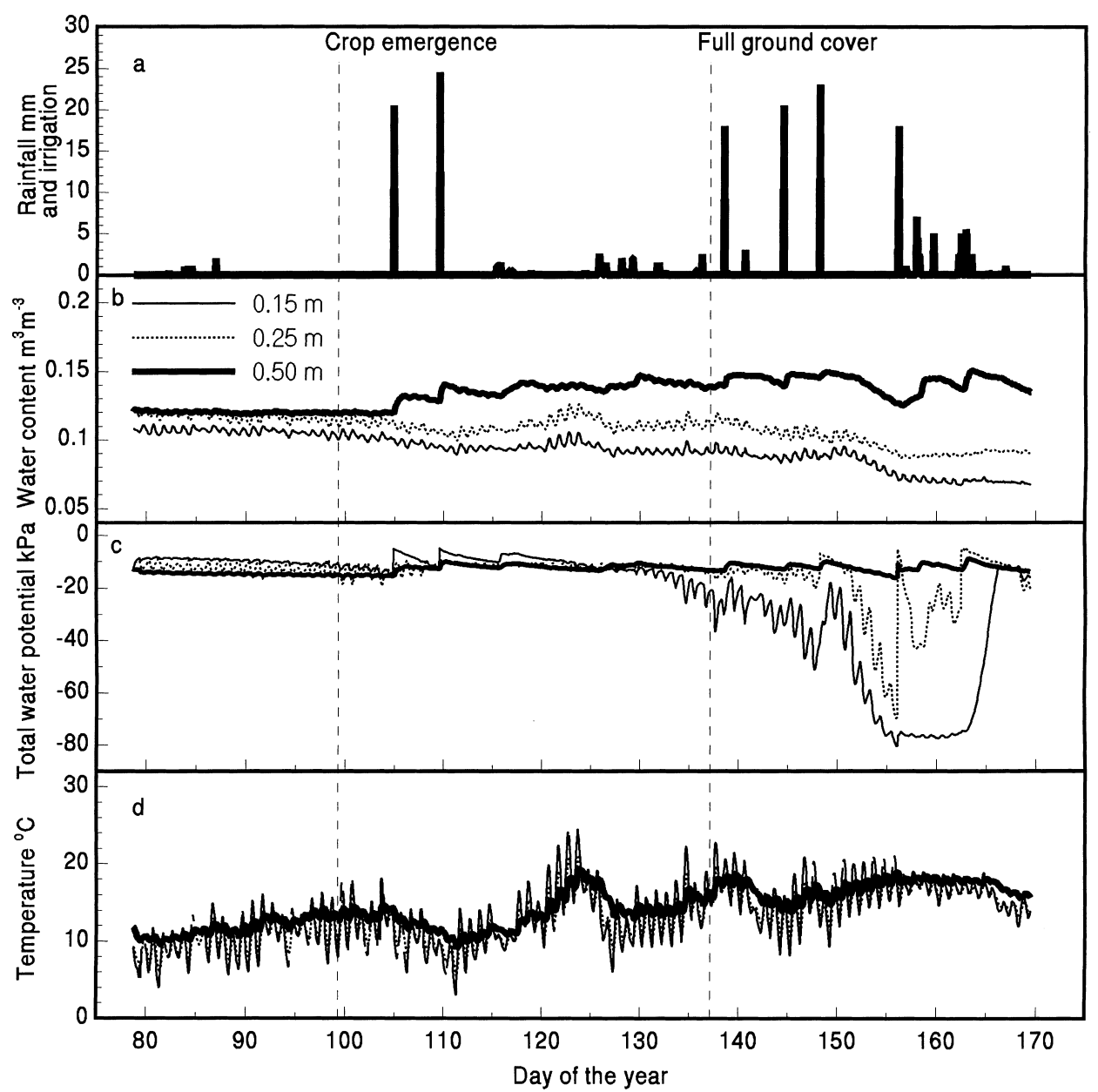

Fig. 3. (a) Rainfall and irrigation; (b) soil water content; (c) hydraulic potential; (d) soil temperature, all soil measurements at $0.15,0.25$ and $0.5 \mathrm{~m}$ below the top of the ridge in the first potato crop.

$0.25 \mathrm{~m}$ sensors showed little reaction to this irrigation. The first rise in water content was measured by the $0.5 \mathrm{~m}$ sensor. It was expected that any measured rise in water content would be sensed first at the shallowest sensor within the ridge $0.15 \mathrm{~m}$ and then at $0.25 \mathrm{~m}$ as the soil wetted. However, over the following 10 days the 0.15 and $0.25 \mathrm{~m}$ sensors showed a decrease in measured soil water content Fig. 3(b). This conflicted with the tensiometer data Fig. 3(c) which showed the soil wetting slightly for the same period. During the second irrigation on day 109 it was found that as the irrigator passed over, water was sprayed onto the access tubes in which the tensiometers were installed. To eliminate the possibility of water collecting and running down the side of the access tube into the soil immediately around the tensiometer cup plastic skirts were fitted around the tensiometer tops to shed the water out onto the surrounding soil. 
The soil water contents measured between days 105 and 115 seemed quite anomalous as $45 \mathrm{~mm}$ of irrigation water was applied but there was no associated increase in water content in the soil at 0.15 or $0.25 \mathrm{~m}$; indeed at these depths the water content decreased by about 0.01 . As the season progressed the same pattern was observed with the water content declining in the ridge and wetting occurring at $0.5 \mathrm{~m}$. A little wetting occurred within the ridge after the rain events on days 115, 126, 157 and 162 but the irrigations appear to have had little or no effect. This lack of soil moisture recharge within the ridge resulted in a distinct soil water deficit developing through the lifetime of the crop (Fig. 6(a)). This gradual build up of a deficit within the ridge was supported by the tensiometer data which showed gradual drying then a large decrease of potential from day 130 onwards.

The soil temperature showed a large diurnal range at 0.15 and $0.25 \mathrm{~m}$ (Fig. 3(d)). The range at $0.15 \mathrm{~m}$ was as large as $8^{\circ} \mathrm{C}$ with $4^{\circ} \mathrm{C}$ at $0.25 \mathrm{~m}$. Two late frosts occurred on days 111 and 127, with the former being the most severe; both frosts set the crop back. From day 119 the daytime soil temperature at $0.15 \mathrm{~m}$ stayed above $15^{\circ} \mathrm{C}$.

\subsection{Field observations}

After each irrigation there was a noticeable difference between the colour of the soil making up the ridge and that which was in the furrow. The wetter soil in the furrow appeared much darker and the soil surface appeared to be a stripy brown.

The photograph in Fig. 4 shows a cross section through a ridge. It was taken after a rainstorm on day 162, the soil was dug back, observed and photographed. After $25.0 \mathrm{~mm}$ of rain the core of the ridge was clearly dry. The dry core within the ridge was observed every time a cross section was dug through one of the ridges. This was carried out five times at different locations around the field during the growing period. It was observed that a 30-40 mm layer of soil wetted at the surface of the ridge, the water then flowed along this conductive pathway, into the furrow where it infiltrated. The dry ridge core developed early in the season and became dryer as the crop extracted more water. The water repellent

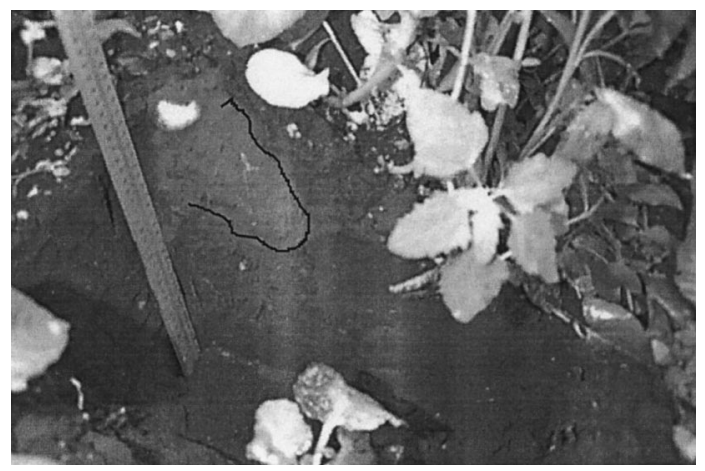

Fig. 4. A photograph of a section through the ridge; the light coloured region of soil highlighted by the black line is dry and clearly visible. The water content of this zone was measured using a capacitance probe and found to have a water content of 0.06 even after $25 \mathrm{~mm}$ of rain had just fallen. 
nature of the soil encouraged this process, the drier the antecedent conditions of the soil the more it impeded water penetration. This is the reason why the water content sensors at 0.15 and $0.25 \mathrm{~m}$ showed a gradual drying throughout the growth of the first crop (Fig. 3(b)).

ASWS results; second potato crop (bed cultivation).

\subsection{Rainfall and irrigation}

The soil was cultivated for a second time in late June/early July. This time the potatoes were planted in beds $\sim 1.25 \mathrm{~m}$ across with three rows in each bed. The $66 \mathrm{~mm}$ of rain which fell in late June early July thoroughly wetted the soil bringing the water content up to field capacity. However, after the cultivation and planting no rain fell for about a week, this allowed the soil surface to dry so that the soil had a similar water repellency as experienced with the ridge cultivation. The ASWS was installed for the second time on the 14th of July (5 days after planting) for 77 days, during which $146.5 \mathrm{~mm}$ of rain fell on the field and $151 \mathrm{~mm}$ of irrigation was applied giving a total input of $297.5 \mathrm{~mm}$ of water. The average irrigation for the eight applications was $18.8 \mathrm{~mm}$ though this contained some variability having a standard deviation of $4.5 \mathrm{~mm}$.

\subsection{Soil water content, potential and temperature}

The data for the second crop is presented in Fig. 5. The time between the crop emerging and full ground cover being achieved was shorter as expected. The sensors installed in the beds responded to the irrigations and rainfall, the soil wetting and draining at each event. The recorded soil temperatures were at their highest for the summer months of July and August and declined steadily in September.

The wetting and drying in the bed was the type of response which had been expected but not observed for the first crop. Infiltration occurred into the bed and so the soil water deficit was reduced after each irrigation (Fig. 5). A lag was observed between the wetting of the soil at the top of the ridge and the sensor responding at $0.5 \mathrm{~m}$ (day 204-205). By day 225 this lag had gone and the sensors all responded together. Emergence occurred around day 205. The irrigations proved to be very effective at rewetting the bed and maintaining the water content close to field capacity during the period of tuber initiation (day 210-240). In the week after full ground cover was achieved (day 225-232), the response of the capacitance probes clearly indicated that the crop was effectively drawing water from 0.15 and $0.25 \mathrm{~m}$; by day 250 the same was occurring at $0.5 \mathrm{~m}$. Once again the capacitance probe data is supported by the tensiometer data (Fig. 5(c)). The tensiometer at $0.5 \mathrm{~m}$ failed to work initially and was replaced at the end of August.

The soil temperature at all depths hovered around $20^{\circ} \mathrm{C}$ during July and August and showed daily maximums of $\sim 25^{\circ} \mathrm{C}$ at $0.15 \mathrm{~m}$. The cable to the $0.5 \mathrm{~m}$ thermistor was found to be damaged and was replaced on day 210 .

\subsection{Soil water storage}

Soil water storage was calculated for the upper $0.3 \mathrm{~m}$ of soil containing the potato crop for both sets of data. The graphs (Fig. 6(a-b)) are based on the water content 


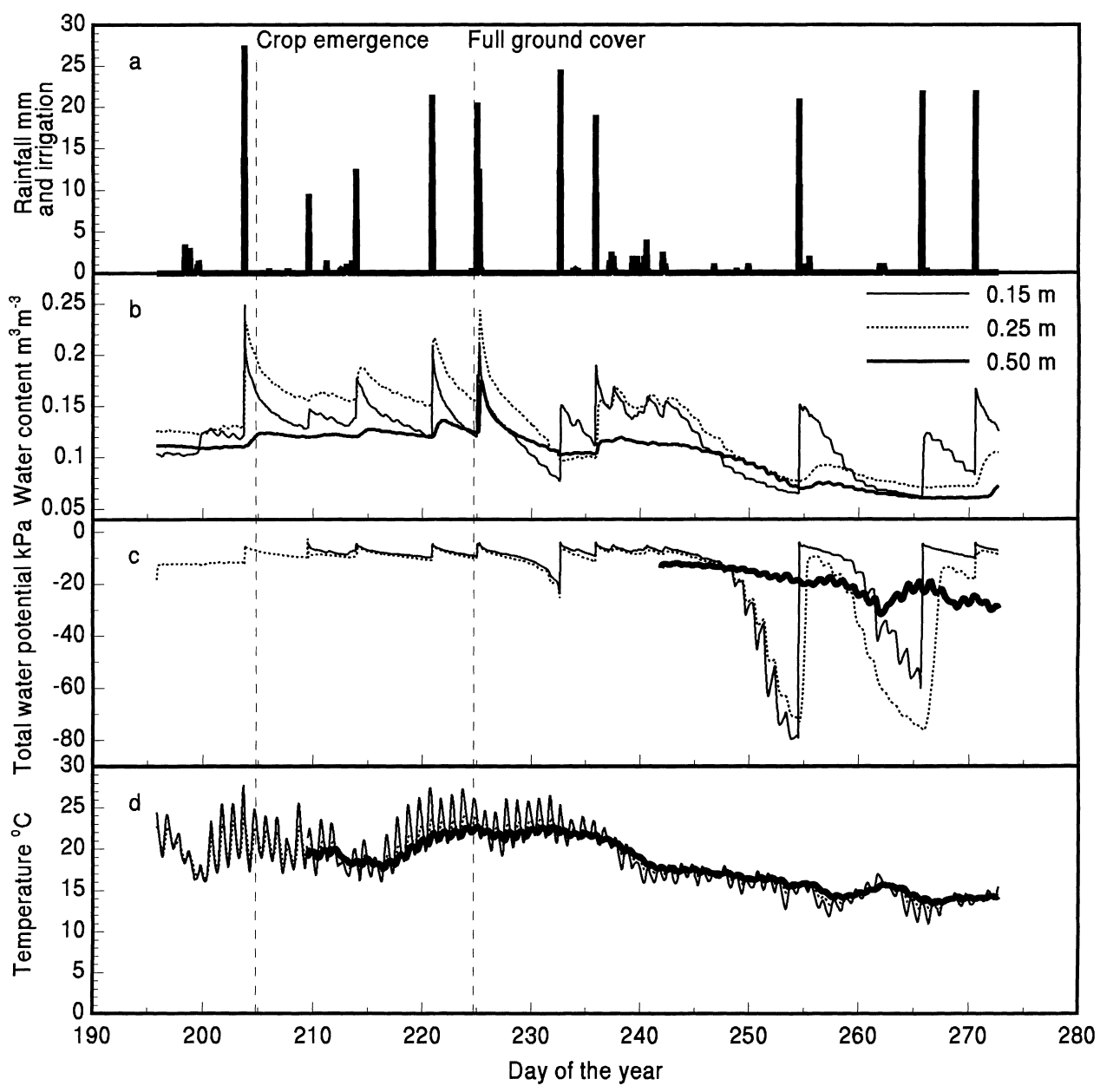

Fig. 5. (a) Rainfall and irrigation; (b) soil water content; (c) hydraulic potential; (d) soil temperature, all soil measurements at $0.15,0.25$ and $0.5 \mathrm{~m}$ below the top of the bed in the second potato crop.

measurements made by the capacitance probes. The water contents measured by the capacitance probe at 0.15 and $0.25 \mathrm{~m}$ were assumed to represent soil layers of $0.1-0.2 \mathrm{~m}$ and $0.2-0.3 \mathrm{~m}$ of soil, respectively; $0.0-0.1 \mathrm{~m}$ was calculated from the measurement at $0.15 \mathrm{~m}$ by subtracting a water content of 0.02 .

A distinctive soil water deficit was found to increase during the first crop in the $0.3 \mathrm{~m}$ of soil below the ridge top. The graph of soil water deficit (Fig. 6(a)) exhibits diurnal fluctuations; these are most probably due to temperature fluctuations influencing the measurement of relative permittivity. The reason for the deficit was that the irrigation water did not penetrate the ridge rewetting the soil, this forms the basis of the discussion later on.

The graph for the second crop was as expected for both crops and cultivation methods (Fig. 6(b)). Between days 200 and 225 the irrigations keep the soil wet and above field 

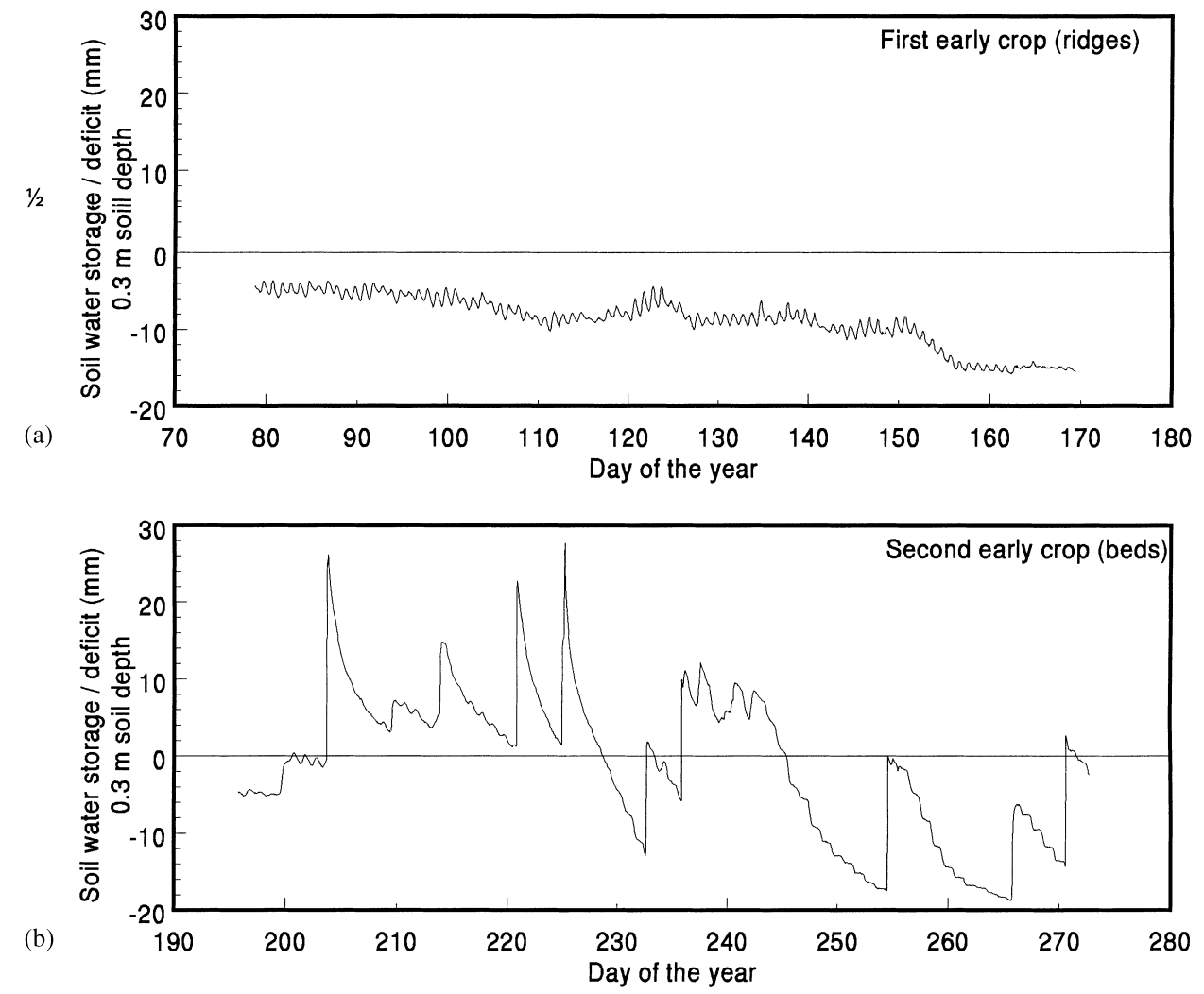

Fig. 6. (a) The soil water deficit for the upper $0.3 \mathrm{~m}$ of soil beneath the ridge, calculated from the capacitance probes located in the ridge. (b) The soil moisture deficit/surplus for the upper $0.3 \mathrm{~m}$ of soil beneath the top of the bed, determined from the capacitance probes located in the bed.

capacity in the upper $0.3 \mathrm{~m}$ of soil. After full ground cover has been reached ( $\sim$ day 225 ) more water is extracted from the soil by the crop resulting in a deficit, replenished by subsequent irrigations.

\subsection{In situ water release}

The infiltration of water into the beds and the subsequent drying allowed for the production of in situ soil water release curves with the very wet end present. The data for 0.15 and $0.25 \mathrm{~m}$ was very complete, throughout the working range of the tensiometers (Fig. 7). Below a water content of 0.10 the matric potential declines rapidly and which may reduce the unsaturated hydraulic conductivity of the soil slowing the redistribution of water within the soil profile. The graph further demonstrates that the water available to the crop is very limited; effectively between 0.25 at saturation and 0.08 . Below a water content of 0.08 the crop has to work progressively harder to draw water from the soil. 


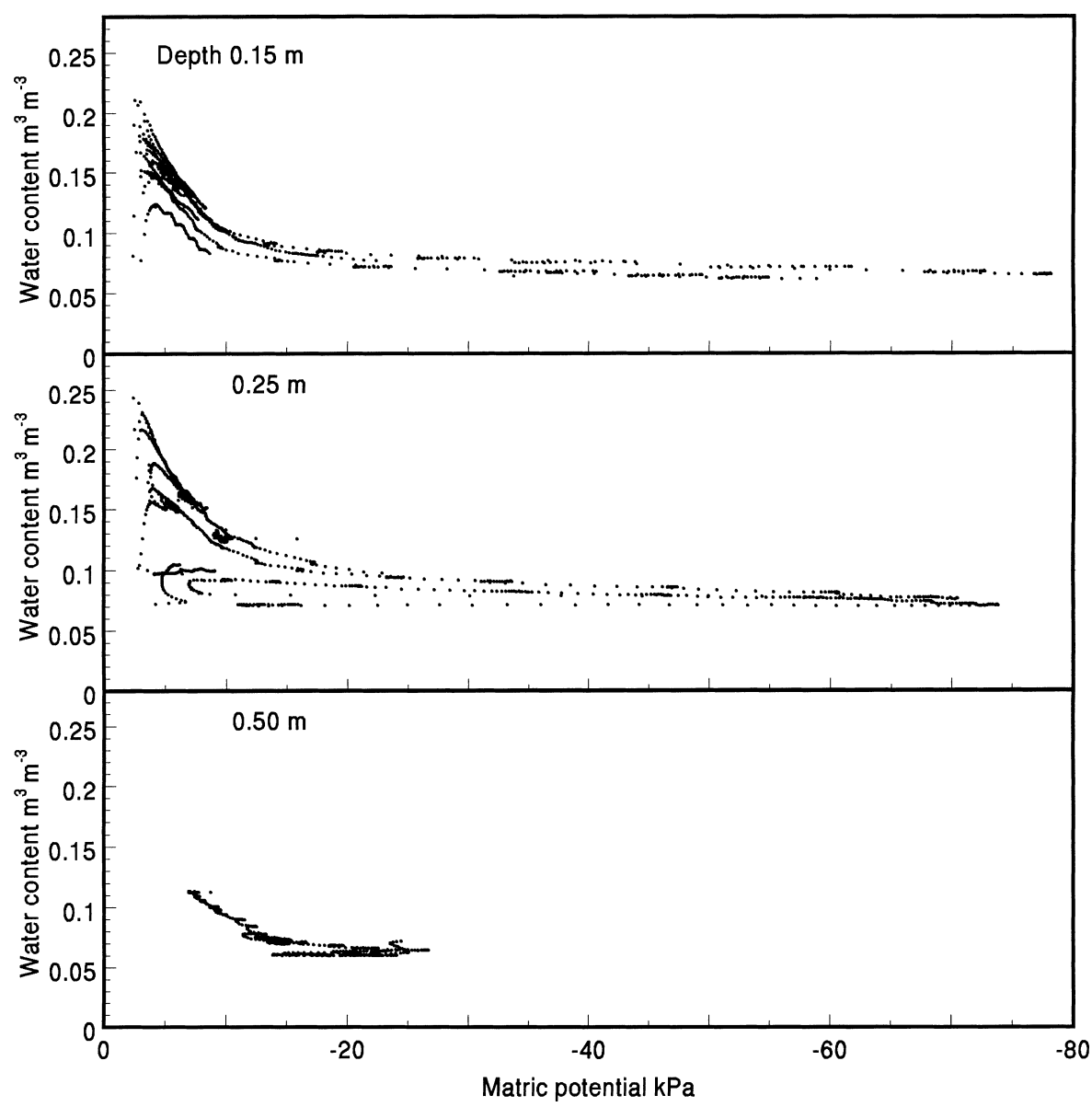

Fig. 7. In situ soil water release curves plotted from the capacitance probe and tensiometer data. Top $0.15 \mathrm{~m}$, middle $0.25 \mathrm{~m}$ and bottom $0.5 \mathrm{~m}$ below soil surface.

\subsection{Conceptual models of infiltration into ridge and bed cultivation}

The data for the first crop planted in the ridges indicates an increase in the soil water deficit at 0.15 and $0.25 \mathrm{~m}$ during the growing time of the crop, despite irrigation and rainfall inputs. This interpretation is based on the reduction of soil water content measured by the capacitance sensors at 0.15 and $0.25 \mathrm{~m}$ Fig. 3. Observation of the first two irrigations applied to the crop suggested that the water that was applied from the boom was shed off the ridges and into the lowest point of the furrow where it ponded and infiltrated. This may have two causes; the first being the slope of the ridges composed of a water repellent soil; the second being the rate at which water is applied from the boom. Nineteen $\mathrm{mm}$ of water was applied to each square metre of soil in one and half minutes. A typical rainstorm will apply $5-10 \mathrm{~mm} \mathrm{~h}^{-1}$ and a thunderstorm as much as $50 \mathrm{~mm} \mathrm{~h}^{-1}$. 
Therefore, the application rate is nearly 150 times greater than a rainstorm and 15 times greater than a UK thunderstorm. Though the sandy soil may have a high saturated hydraulic conductivity (e.g. $2.1 \times 10^{-4} \mathrm{~m} \mathrm{~s}^{-1}$ ), the slope of the ridges and water repellency of the soil when dry may prevent the water from penetrating the ridges. This may be reduced by slowing the irrigation application rate and the rate of travel of the irrigator over the field. This will be most important soon after cultivation and early in the life of the crop. If the dry repellent surface can be wetted early on, infiltration should be 'normal' so long as the dry repellent surface is prevented from redeveloping by subsequent irrigation.

The shedding of water into the furrows is likely to be exacerbated as the crop emerges and grows (Saffigna et al., 1977; Curwen and Massie, 1984). The canopy of the crop may act rather like an umbrella, again causing water to be shed into the furrows. The canopy may have some positive effect, gathering water which may flow down the stem and infiltrate at the base of the stem directly on to the potatoes. However, this was not observed in the field. The weight of the water on the canopy bent the leaves down and so intercepted water was shed into the furrows. Based on the ASWS data (Fig. 3) and the field observations (Fig. 4). Fig. 8 shows a conceptual diagram showing the major water flow pathways within the soil for a ridge cultivation system.

The change to bed cultivation for the second crop resulted in a substantial improvement in terms of water penetration into the soil around the potatoes. The level surface of the bed allowed more water to be captured and held on the soil surface providing time for it to infiltrate. Some water was observed to run off the edges of the beds as it was applied from the irrigator but the instruments and observation of the bed in cross section, demonstrated good water penetration. This is shown in a conceptual diagram, Fig. 9.

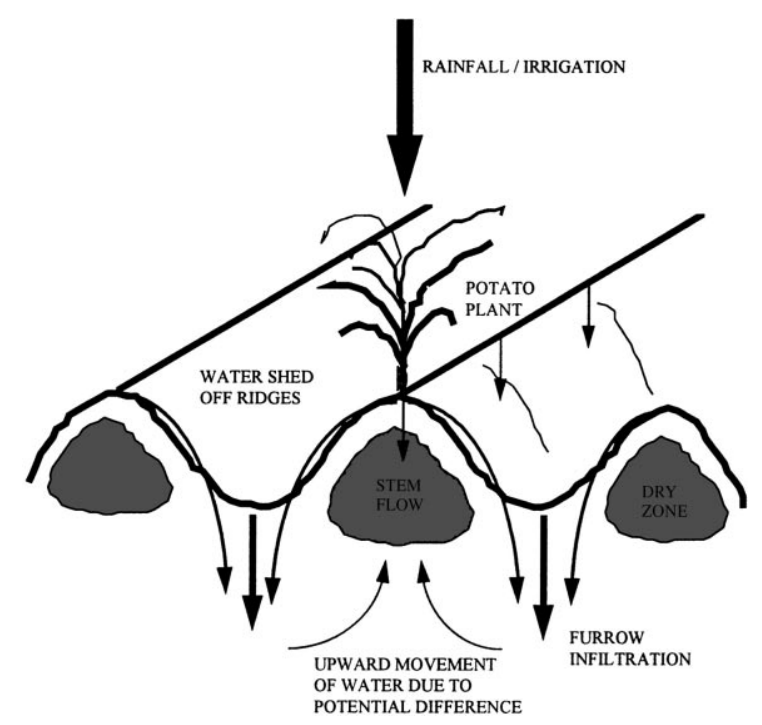

Fig. 8. Conceptual diagram of water infiltration pathways for a potato crop planted in ridges. 


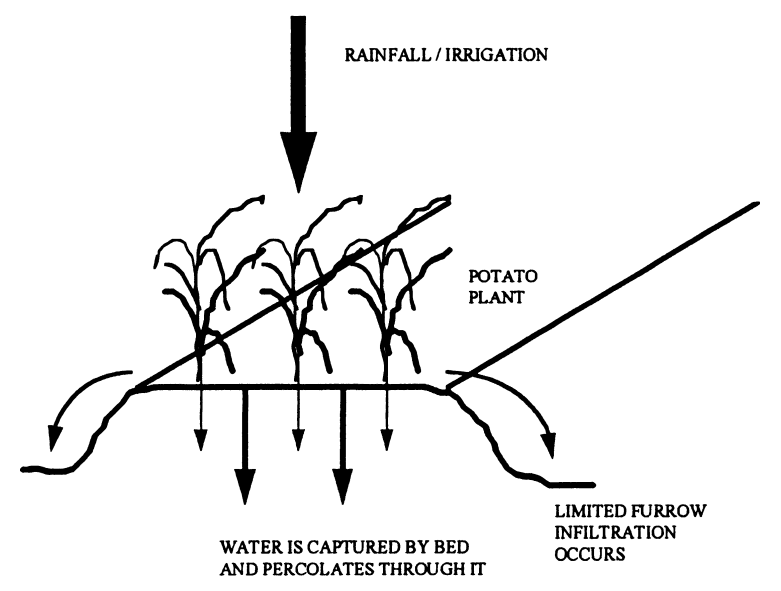

Fig. 9. Conceptual diagram of water infiltration into the bed cultivation system.

This work clearly demonstrates that much can be learned from the collection of high resolution data in the soil, around the crop. Data from traditional field trials should be treated cautiously when water repellency is suspected and assumptions are made about the amount of water reaching the crop. Calculations of yield based on the amount of irrigation water applied to the first crop would be erroneous as most of the applied water never reached the crop. Field trials incorporating this style of technology to understand soil water processes provide a comprehensive way of studying crop/water response.

\subsection{Soil water management and disease control}

The results from this experiment have some major implications for the way water is applied to potato crops grown in water repellent sandy soils. Potatoes are conventionally cultivated in ridges and watered for growth, frost protection and disease control, especially scab prevention (Bailey, 1990). The evidence from this work suggests that water management with these aims will only be achieved by preventing or breaking down the infiltration barrier created with the ridge cultivation or by using beds. One of the main reasons for using ridges is to capture as much warmth as possible from the low intensity spring sunshine. A useful contribution would be to determine how much of an advantage ridge cultivation offers over bed cultivation in terms of the soil thermal regime and its subsequent contribution to crop growth and yield. This work suggests that any advantage of higher temperatures in ridge cultivation could be completely lost by inadequate protection from frost due to low soil water content.

Recommendations to improve water management based on this data are:

Reduce the hydrophobicity of the soil early in the year before a dry hydrophobic crust forms when using ridge cultivation. This may be achieved either by thoroughly wetting the soil using a large application of water applied at a slower rate soon after tillage. 
Alternatively a wetting agent sprayed onto the surface prior to crop emergence could be used to enhance water penetration. If the use of wetting agents can be avoided this is both beneficial to the environment and more cost effective to the grower. The data suggests that the use of bed cultivation would be a strong alternative to ridge cultivation to improve water management. However, further work is required to determine if the thermal regime of the beds is sufficient to allow an early harvest and sustain crop yields.

\section{Conclusions}

The data presented in this study demonstrated that applied irrigation and rain water was not penetrating soil ridges in which potatoes were planted. The water was shed off the ridges due to the water repellency of the soil and collected and infiltrated in the furrows. The implications for management are two-fold. First, being that water applied may not be entering the soil where the grower assumes it is, thus the deficit is not reduced and gradually builds within the ridge, especially once the potatoes begin to transpire effectively. The second issue concerns quality, scab is prevented by keeping the surface of the potato moist, if the deficit increases and applied irrigation bypasses the potatoes the likelihood of scab infection is increased.

\section{Acknowledgements}

The author would like to thank the Chadacre Agricultural Trust for its support during this work and Upton Suffolk Farms for their commitment to the experimental science aimed at improving water management. My thanks to David Cooper, Cate Gardner, Martin Hodnett, and John Bell from the Institute of Hydrology and Steve Gaze and others from Cambridge University Farm for discussions and assistance during this work. My thanks to the two anonymous reviewers for their help in improving this paper.

\section{References}

Avery, B.W., 1980. Soil classification for England and Wales. Soil Survey Tech. Monographs No. 14.

Bailey, R., 1990. Irrigated Crops and Their Management. Farming Press Books, Ipswich, UK.

Curwen, D., Massie, L.R., 1984. Potato irrigation scheduling in Wisconsin. Am. Potato J. 61, 235-241.

Dean, T.J., 1994. The IH capacitance probe for measurement of soil water content. IH Report No. 125. Institute of Hydrology, Wallingford, Oxon.

Gardner, C.M.K., Dean, T.J., Cooper, J.D., 1998. Soil water content measurement with a high frequency capacitance sensor. J. Agric. Eng. Res. 71, 395-403.

Gaskin, G.J., Miller, J.D., 1996. Measurement of soil water content using a simplified impedance measuring technique. J. Agric. Eng. Res. 63, 153-160.

Haria, A.H., Johnson, A.C., Bell, J.P., Batchelor, C.H., 1994. Water movement and isoproturon behaviour in a drained heavy clay soil: 1. Preferential flow processes. J. Hydrol. 163, 203-216.

Krammes, J.S., DeBano, L.F., 1965. Soil wettability: a neglected factor in watershed management. Water Resources Res. 1(2), 283-286. 
Perdok, U.D., Kroesbergen, B., Hilhorst, M.A., 1996. Influence of gravimetric water content and bulk density on the dielectric properties of soil. Eur. J. Soil Sci. 47, 367-371.

Robinson, D.A., Gardner, C.M.K., Evans, J., Cooper, J.D., Hodnett, M.G., Bell, J.P., 1998. The dielectric calibration of capacitance probes for soil hydrology using an oscillation frequency response model. Hydrol. Earth System Sci. 2, 83-92.

Saffigna, P.G., Tanner, C.B., Keeney, D.R., 1977. Non-uniform infiltration under potato canopies caused by interception, stemflow and hilling. Agronomy J. 68, 337-342.

Singh, G., Brown, D.M., Barr, A.G., Jung, R., 1993. Modelling soil water status for irrigation scheduling in potatoes II. Validation. Agric. Water Manage. 23, 343-358.

Stansfield, C., 1996. Water for food - agricultural irrigation. CIWEM Symposium, Water Resources - Planning for Peak Demands. pp. 1-8.

Topp, G.C., Davies, J.L., Annan, A.P., 1980. Electromagnetic determination of soil water content: measurements in coaxial transmission lines. Water Resources Res. 16, 574-582.

Topp, G.C., Davies, J.L., 1985. Time-domain reflectometry (TDR) and its application to irrigation scheduling. In: Hillel, D. (Ed.), Advances in Irrigation, vol. 3. Academic Press, London, pp. 107-127. 